\title{
On the locus of redundancy effects in a letter-detection task
}

\author{
JAY G. RUECKL and SATORU SUZUKI \\ Harvard University, Cambridge, Massachusetts \\ and \\ SU-LING YEH \\ University of California, Berkeley, California
}

\begin{abstract}
It takes longer to detect a target if it is the initial letter of a nonredundant letter string such as BNHTW than if it is the initial letter of a redundant letter string such as BBBBB (Johnson, $1986 \mathrm{~b}$; Johnson \& Blum, 1988). The results of the present study reveal that the redundancy effect also occurs for mixed-case letters strings (e.g., BbbBb) and digit strings (e.g., 22222). In addition, these results suggest that the cause of the redundancy effect is not related to the visual properties of the noninitial letters per se but is instead related to the presence of the target in noninitial positions. Together, these results rule out a number of hypotheses about the cause of the redundancy effect and suggest that the locus of this effect is in processes involved in response selection and/or the read-out of information from the perceptual system.
\end{abstract}

It is well established that the identification of a letter is influenced by the context in which that letter appears. In many cases, contextual information facilitates letter identification. For example, a letter is more likely to be identified if it is tachistoscopically presented as a component of a word or pronounceable nonword than if it is presented alone or in a random letter string (Reicher, 1969; Wheeler, 1970; for reviews, see McClelland \& Rumelhart, 1981, or Henderson, 1982). In other situations, however, contextual information can impair the processing of a letter. For example, tachistoscopically presented target letters are more likely to be detected when they are presented alone than when they are presented in the context of one other letter, particularly when the context letter is identical to the target letter (Bjork \& Murray, 1977; Egeth \& Santee, 1981).

In the paradigm used in the present study, contextual effects on letter processing are examined by asking subjects to determine as rapidly as possible whether a target letter is present in a visual display. The visual displays consist of either a single letter or a five-letter consonant string, and the subject's task is to determine if the leftmost letter of the display (referred to as the critical letter) matches a prespecified target. In previous studies employing this paradigm, Johnson and his colleagues

This research was supported by grants to the first author from the Defense-University Research Instrumentation Program (DURIP Grant AFOSR-89-0090) and from the Elsie Stimson Memorial Fund. We wish to thank Jon Kolodny for his assistance in conducting the second experiment, and Lester Krueger and three anonymous reviewers for valuable comments on an earlier version of this article. Correspondence should be sent to Jay G. Rueckl, Department of Psychology, Harvard University, Cambridge, MA 02138.
(Johnson, 1986a, 1986b; Johnson \& Blum, 1988; Johnson, Turner-Lyga, \& Pettegrew, 1986) have demonstrated that responses are generally made more quickly when the critical letter is presented alone than when it is presented in the context of other letters. In addition, response latencies are also influenced by the nature of the relationships among the letters in a multiletter display. Specifically, responses are made more quickly when the multiletter string is redundant (i.e., when it contains several instances of the same letter, as in the letter string BBBBB) than when it is nonredundant (i.e., when none of the component letters appears more than once, as in the letter string BNHTW).

Although the single-letter advantage is fairly robust, there are some circumstances in which responses are made as quickly to redundant displays as to single-letter displays (Krueger \& Shapiro, 1980). Whether or not a singleletter advantage is obtained depends on the manner in which visual attention is allocated to the display. Specifically, the single-letter advantage occurs only when the subjects cannot prefocus their attention to a limited area that includes the critical letter but none of the context letters (Johnson \& Blum, 1988).

In comparison to the single-letter advantage, the redundancy effect is extremely robust-it is virtually always the case that a target letter is detected more quickly in a redundant display than in a nonredundant display. However, the mechanism underlying this effect is not well understood. It is possible that the effect arises through response competition; that is, if the letters in the display are identified in parallel, then the noninitial nonredundant letters would signal a response that is incompatible with the response signaled by the critical letter. However, Johnson and Blum (1988) provide several arguments against 
this hypothesis. One argument is that this account only explains the redundancy effect for target-present trials, because, on target-absent trials, both the critical letter and the context letters signal the same "no"' response. Yet, a redundancy effect is often found on both target-present and target-absent trials (Johnson, 1986b; Johnson \& Blum, 1988).

This argument can be countered by assuming that the competition is at the letter-name level rather than at the response level. Under this assumption, nonredundant context letters would provide information that conflicts with the information provided by the critical letter regardless of whether the target is present or absent. However, Johnson and Blum (1988) provide a second argument that applies regardless of whether the competition is at the response or letter-name levels. They note that if the availability of information about either the names or the responses signaled by noninitial letters were responsible for the redundancy effect, one would expect that response latencies on target-absent nonredundant trials would be slowed when the target letter was present in a noninitial position. However, Johnson (1986a) found that the presence of targets in noninitial positions had no effect on how quickly subjects responded on target-absent nonredundant trials.

Johnson and Blum (1988) proposed an alternative account of the redundancy effect. They noted that, if letters are encoded in parallel, the subjects must check to be sure that they are basing their responses on the initial letter, and this check of positional information may slow the response. However, if the subjects knew that a display was redundant, they would not need to perform the positional information check, because the same response would be appropriate regardless of whether it was based on an initial or noninitial letter. Johnson and Blum hypothesized that the physical regularity of a redundant display (i.e., the fact that the component letters of the display are physically identical) may allow a subject to determine that the display is redundant even before the component letters are identified. If this were the case, the subject could opt to not carry out the positional information check, thus resulting in faster responses to redundant than to nonredundant displays.

\section{EXPERIMENT 1}

If Johnson and Blum's hypothesis is correct, it should be possible to eliminate the redundancy effect by forcing subjects to carry out the positional information check on redundant displays. By hypothesis, the position check is carried out unless the subject has advance knowledge that a display is redundant-the fast detection of the physical regularity of a redundant display provides this knowledge. Thus, according to this hypothesis, responses to redundant but irregular displays would be expected to be no faster than responses to nonredundant displays.

A redundant display can be rendered irregular by varying the physical characteristics of the component letters in the display. In Experiment 1, multiletter displays contained a mixture of uppercase and lowercase letters, so that neither redundant (e.g., BbbBb) nor nonredundant (e.g., BnhTw) displays were highly regular. Assuming that this manipulation prevents subjects from quickly determining that a display is redundant, the positional check would be carried out for both redundant and nonredundant stimuli. Thus, on the basis of the position-checking hypothesis, one would predict that the redundancy effect would not occur for mixed-case stimuli. Note, however, that underlying this prediction is the assumption that information about the redundancy of the stimulus was not available from some other source. Subjects could still adopt the strategy of not carrying out the position check for redundant displays if, for example, they were told in advance that a redundant display would be presented on the next trial.

To explore this possibility, half of the subjects in Experiment 1 were given advance information about the characteristics of the upcoming stimulus display. This was accomplished by presenting single-letter, redundant, and nonredundant displays in separate blocks and informing the subjects that stimuli were blocked in this way. On the basis of the position-checking hypothesis, one would predict an advantage for redundant stimuli in the blockedpresentation condition because the subjects could adopt the strategy of omitting the position check. However, when mixed-case stimuli are presented in a random order, no such redundancy effect would be expected.

\section{Method}

Subjects. Thirty-six Harvard University students served as paid subjects.

Design. On each trial, a target was presented and then followed by one of three types of displays. For the single-letter displays, 1 of 20 consonants ( $Y$ was not used) was presented in isolation. For the redundant displays, a string of 5 instances of the same consonant was presented. For the nonredundant displays, a string of five consonants was presented, but no consonant appeared more than once in a given display. For both the redundant and nonredundant displays, uppercase letters were used in the first and fourth positions, and lowercase letters were used in the other positions. The letters presented as targets and in the single-letter displays were also in uppercase.

The target letter matched the critical letter for half the displays (i.e., the yes items) and did not match the critical letter for the other displays (i.e., the no items). Each consonant served as the critical letter for two yes items and two no items of each display type. For the nonredundant displays, the target letter never appeared as one of the noninitial letters. There were 80 displays of each display type, and each display was presented twice, so that there were 480 trials in total.

In the blocked condition, the three types of displays were presented in separate blocks. Each type was presented in two adjacent sets of 80 trials each, and the order of presentation was counterbalanced across subjects. In the unblocked condition, the displays were presented in eight sets of 60 trials, and each set included 20 trials of each display type. In both the blocked and unblocked conditions, half the displays within each set were yes items, and the order of presentation within sets was randomized. Half the subjects were assigned to the blocked condition; the remaining subjects were assigned to the unblocked condition. 
There were six practice trials presented at the beginning of the experiment, including one of each combination of display and response type. The practice stimuli were constructed from the six letters not used during the main experiment (i.e., a, e, i, o, u, y).

Procedure. At the beginning of the experiment, the subjects were informed that the experiment would consist of a number of sets of trials. The subjects in the unblocked condition were told that each set would include all three display types. The subjects in the blocked condition were told that only one type of display would be presented within a set.

Each trial began with a "Press space bar to begin" display. When the subject pressed the space bar, a target letter was presented for $1 \mathrm{sec}$ and was then followed by a row of five dots that served as the predisplay fixation field. The fixation field was displayed for $500 \mathrm{msec}$ and disappeared $350 \mathrm{msec}$ before the presentation of the display. For the single-letter displays, the critical letter appeared in the location that had been occupied by the leftmost of the five dots. For the redundant and nonredundant displays, each letter replaced one of the five dots. The subjects were informed of this relationship and were asked to fixate on the leftmost dot.

When the display appeared, the subject's task was to compare the critical letter to the target letter and either to push the "yes" button as quickly as possible if the critical letter matched the target or to push the "no" button otherwise. The display remained visible until the subject responded, and a computer "beep" provided feedback whenever an erroneous response was made. Half the subjects pushed the "yes" button with their dominant hand; the other half pushed the "yes" button with their nondominant hand. (The " $m$ " and " $v$ " keys of a Macintosh keyboard were used as response buttons.)

The experiment was run on a Macintosh Plus computer, with the monitor set to maximum brightness. The displays consisted of black characters on a white background. Each letter was about $3 \mathrm{~mm}$ wide, and the letters were separated by spaces of $1.5 \mathrm{~mm}$. Thus, at a distance of $67 \mathrm{~cm}$, each letter string subtended about $2^{\circ}$ of visual angle.

\section{Results}

The error rates and reaction time (RT) data for Experiment 1 are presented in Table 1 . Error rates varied significantly as a function of response type, with more errors made on yes trials than on no trials $[F(1,34)=$ $17.442, p<.001]$. However, error rates did not vary significantly as a function of display type $(F<1)$. The only other significant effect was the three-way interaction of display type, response type, and grouping condition $[F(2,68)=3.141, p<.05]$.

Table 1

Mean Response Time (RT; in Milliseconds) and Percent Error Rate (PE) as a Function of Blocking, Display Type, and Response in Experiment 1

\begin{tabular}{|c|c|c|c|c|c|c|}
\hline \multirow[b]{3}{*}{ Response } & \multicolumn{6}{|c|}{ Display Type } \\
\hline & \multicolumn{2}{|c|}{ Single } & \multicolumn{2}{|c|}{ Redundant } & \multicolumn{2}{|c|}{ Nonredundant } \\
\hline & RT & PE & RT & $\mathrm{PE}$ & RT & PE \\
\hline \multicolumn{7}{|c|}{ Unblocked } \\
\hline Yes & 538 & 2.87 & $\begin{array}{l}562 \\
565\end{array}$ & 1.68 & $\begin{array}{l}579 \\
581\end{array}$ & 3.77 \\
\hline No & 571 & 1.48 & 565 & 1.83 & 581 & \\
\hline Mean & 554 & 2.18 & 564 & 1.76 & 580 & 2.59 \\
\hline \multicolumn{7}{|c|}{ Blocked } \\
\hline Yes & $\begin{array}{l}479 \\
527\end{array}$ & 2.59 & 513 & 2.80 & 500 & 2.45 \\
\hline No & 527 & 1.27 & 556 & 1.48 & 527 & 1.33 \\
\hline Mean & 503 & 1.93 & 534 & 2.14 & 514 & 1.89 \\
\hline
\end{tabular}

In the analysis of the RT data, trials on which an error was made, or on which the RT differed from the individual subject mean by more than two standard deviations, were discarded. This analysis revealed that $\mathrm{RT}$ varied as a function of display type $[F(2,68)=7.024, p<.01]$ and response type $[F(1,34)=12.056, p<.01]$ and that the interaction of these effects was also significant $[F(2,68)$ $=4.075, p<.05]$. Yes responses were faster than no responses-this effect was largest in the single-letter condition and smallest in the nonredundant condition. The main effect of blocking condition was not significant $[F(1,34)=1.490, p>.20]$. However, the interaction of blocking condition and display type was significant $[F(2,68)=5.012, p<.01]$; the interaction of blocking condition and response type approached significance as well $[F(1,34)=3.038, p<.10]$.

In order to evaluate the position-checking hypothesis, a set of planned comparisons was conducted to examine the effect of display type within each blocking condition. In the unblocked condition, responses were made more quickly to single-letter displays (collapsed across response type) than to either redundant $[F(1,17)=6.462, p<.05]$ or nonredundant $[F(1,17)=35.638, p<.001]$ displays. In addition, responses were made more quickly to redundant displays than to nonredundant displays $[F(1,17)=$ $10.152, p<.01]$. Moreover, the advantage of redundant displays was also apparent when yes $[F(1,17)=4.867$, $p<.05]$ and $n o[F(1,17)=7.768, p<.05]$ responses were considered separately.

A different pattern of results occurred in the blocked condition. Here, although a single-letter advantage was found in comparison with redundant displays $[F(1,17)=$ $7.527, p<.05$ ], no such advantage was found in comparison with nonredundant displays $[F(1,17)=1.692$, $p>$.20]. More importantly, the difference in RT for the redundant and nonredundant displays was not reliable, neither when scores were collapsed across yes and no trials $[F(1,17)=2.686, p>.10]$ nor when yes $[F(1,17)=$ $1.420, p>.20]$ or $n o[F(1,17)=2.349, p>.10]$ trials were considered separately.

\section{Discussion}

According to the position-checking hypothesis, prior knowledge of the display type in the blocked condition should have allowed the subjects to forgo the position check and thus should have resulted in a response-time advantage for the redundant displays over the nonredundant displays. In contrast, in the unblocked condition, the use of mixed-case stimuli should have prevented subjects from omitting the position check and thus should have resulted in the lack of a redundancy effect. In fact, just the opposite pattern of results obtained. A redundancy effect was found in the unblocked condition but not in the blocked condition. Thus, the results of Experiment 1 appear difficult to reconcile with the position-checking hypothesis.

One aspect of the results warrants further discussion. In the blocked condition, responses to redundant stimuli were not faster than responses to nonredundant stimuli 
(indeed, there was a nonsignificant trend in the opposite direction). This finding is surprising in light of previous studies (Johnson, 1986a, 1986b; Johnson \& Blum, 1988; Johnson et al., 1986), in which an advantage for redundant stimuli has consistently been reported. One possible explanation of this seemingly anomalous finding is that the blocking of the stimuli may have led the subjects to adopt a suboptimal strategy not employed when redundant and nonredundant stimuli are presented together (as in the previous studies and the unblocked condition of Experiment 1). For example, when the subjects knew that the stimuli were redundant, they may have focused their visual attention over the entire string rather than narrowing their attention to a single letter, slowing the rate at which individual letters are identified.

\section{EXPERIMENT 2}

In the following experiments, several alternative explanations of the redundancy effect were investigated. One possibility, suggested in part by Johnson and Blum's (1988) results, is that the redundancy effect is due to relatively early visual processes. Johnson and Blum found that the advantage of single-letter over multiletter displays depends on how subjects prefocus their attention. When information was available to allow subjects to prefocus on a sufficiently narrow visual area, response times were not influenced by the presence of context letters in the display. Thus, early selective attention appears to play an important role in the performance of this task.

Perhaps attentional processes are also responsible for the redundancy effect. Suppose that to identify the initial letter of a multiletter display, a subject must focus his or her "attentional window" so that it only encompasses that letter. It is possible that the time needed to focus attention on the first letter is influenced by the visual characteristics of the display. For example, it may be easier to focus attention on a component of a relatively homogeneous, regular display (perhaps because it is easier to parse a regular display into its parts).

Experiment 2 tests this hypothesis. In order to disconfound physical regularity and the number of instances of the target letter in the display, digits were used in the noninitial positions of the multicharacter displays. In the regular-context condition, four instances of the same digit occupied the noninitial positions (e.g., B2222). In the irregular-context condition, four different digits were used (e.g., B2583). If differences in the regularity of the displays underlie the redundancy effect, then responses should be made more quickly in the regular-context condition.

\section{Method}

Except for differences in stimuli, this experiment was identical to the unblocked condition of Experiment 1. Again, three types of displays were presented. The single-letter displays were those used in the previous experiment. Regular-context displays consisted of a letter followed by four instances of the same digit. Irregular-context displays consisted of a letter followed by four different digits. All
Table 2

Mean Response Time (RT; in Milliseconds) and Percent Error Rate (PE) as a Function of Display Type and Response in Experiment 2

\begin{tabular}{|c|c|c|c|c|c|c|}
\hline \multirow[b]{3}{*}{ Response } & \multicolumn{6}{|c|}{ Display Type } \\
\hline & \multicolumn{2}{|c|}{ Single } & \multicolumn{2}{|c|}{ Regular } & \multicolumn{2}{|c|}{ Irregular } \\
\hline & RT & PE & RT & PE & RT & PE \\
\hline $\begin{array}{l}\text { Yes } \\
\text { No }\end{array}$ & $\begin{array}{l}466 \\
524\end{array}$ & $\begin{array}{l}5.65 \\
5.41\end{array}$ & $\begin{array}{l}511 \\
534\end{array}$ & $\begin{array}{l}6.04 \\
4.82\end{array}$ & $\begin{array}{l}505 \\
535\end{array}$ & $\begin{array}{l}6.23 \\
5.42\end{array}$ \\
\hline Mean & 495 & 5.53 & 522 & 5.43 & 520 & 5.82 \\
\hline
\end{tabular}

digits except 1 and 0 were used, and each digit appeared equally often in each position of both the regular- and irregular-context displays. The subjects were 48 Harvard University students who were paid to participate in this experiment.

\section{Results}

The data from Experiment 2 are presented in Table 2. More errors were made on yes trials than on no trials $[F(1,47)=6.603, p<.05]$. However, error rates did not vary significantly as a function of display type $(F<1)$, nor was the interaction of display type and response type significant $[F(2,94)=1.148, p>.20]$.

The RT analysis revealed a significant effect of display type $[F(2,94)=34.518, p<.001]$. More specifically, responses were made more quickly to single-letter displays than to regular-context displays $[F(1,47)=31.807$, $p<.001]$ or to irregular-context displays $[F(1,47)=$ $54.680, p<.001]$. In contrast, RT to regular- and irregular-context displays did not differ significantly $(F<1)$. Finally, both the effect of response type $[F(1,47)$ $=33.264, p<.001]$ and the interaction of response type and display type $[F(2,94)=17.981, p<.001]$ were significant: Subjects made yes responses more quickly than no responses, and this difference was greatest in the single-letter condition.

\section{Discussion}

Response latencies in Experiment 2 were not influenced by the regularity of the digit context in which the critical letter appeared, suggesting that the redundancy effect observed in previous experiments (Johnson, 1986a, 1986b; Johnson \& Blum, 1988; Johnson et al., 1986) is not due to the influence of context homogeneity/heterogeneity on the attentional focusing process. It should be noted, however, that this result does not completely eliminate the focusing process as a possible locus of the redundancy effect. It could be that the focusing process is influenced by other factors, such as the similarity between the critical letter and its nearest neighbor. (We return to this issue in the General Discussion.)

A comparison of the regularity manipulation of the present experiment with the contextual manipulations that influenced RT in Experiment 1 and elsewhere suggests several other factors that could play a role in the redundancy effect. First, perhaps context effects in this task only occur when both the critical item and the context items are letters (or, more generally, when the critical 
and context items belong to the same category; i.e., letters or digits). Second, perhaps for these context effects to occur, more than one instance of the critical item must appear in the display. The following experiments investigate these possibilities.

\section{EXPERIMENT 3}

In the next experiment, digits were used as both critical and context items. One motivation for this change was the desire to determine whether the redundancy effect occurs for stimuli other than letter strings. In addition, the use of digits provides a test of the hypothesis that the redundancy effect is related to interference from wordlevel representations in the attempt to access letter-level information.

It has often been proposed that the encoding of a visual stimulus occurs at a number of levels of representation. For example, hierarchical models of word perception assume that the identification of a word involves the activation of representations at the feature, letter, and word levels (Johnston \& McClelland, 1980; McClelland \& Rumelhart, 1981). Under some conditions, the activation of higher-level representations can facilitate processing at lower levels. Thus, McClelland and Rumelhart (1981) proposed that cooperative feedback from word units to letter-level units underlies the facilitatory effect of orthographic regularity on letter identification in tachistoscopic tasks (Johnston \& McClelland, 1980; Reicher, 1969). However, under other conditions, competition between levels may have deleterious effects. For example, if the order in which attention is deployed to the various levels is biased in favor of the word level, then the ability to make speeded responses on the basis of letter-level information would be impaired by the activation of word representations (for discussions of similar proposals, see Healy, 1976; Henderson, 1982; Johnson \& Blum, 1988; Johnson et al., 1986).

If competition between word- and letter-level information influences performance on speeded detection tasks, then the magnitude of this effect would be related to the degree to which stimuli resemble familiar words. Although neither redundant nor nonredundant displays are particularly wordlike, it is generally easier to find fiveletter words that overlap in three or four positions with nonredundant stimuli than with redundant stimuli. If even small amounts of word-level activation interfere with access to letter-level information, this difference could result in slower latencies for nonredundant displays.

It seems reasonable to assume that few five-digit strings are highly familiar to many subjects (certain ZIP codes being possible exceptions). If anything, subjects are more likely to have previously encountered some of the 8 redundant five-digit strings than any of the $\mathbf{3 2}$ nonredundant five-digit strings. Thus, the occurrence of a redundancy effect in the present experiment could be taken as evi- dence against the hypothesis that the redundancy effect is related to response-level interference by pattern-level information.

\section{Method}

Subjects. Twenty-four Harvard University undergraduates served as paid subjects.

Design and Procedure. Eight digits were used to construct the targets and displays ( 0 and 1 were excluded). Redundant displays consisted of five instances of the same digit (e.g., 22222). Nonredundant displays consisted of five different digits arranged in a random order (e.g., 28463). For the nonredundant displays, each digit appeared equally often in each position, and no digit appeared more than once in a display. Moreover, on both yes and no trials, a target digit never appeared in a noninitial position. Each digit served as the critical digit on two yes items and two no items of each display type. Thus, there were 32 different displays of each type (single-digit, redundant, and nonredundant) and 96 displays in total. Each subject completed four blocks of trials, and all 96 displays were presented in each block. Within each block, the displays were presented in a random order and were not blocked by type.

Before performing the experimental trials, the subjects completed 12 practice trials. The practice stimuli included equal numbers of yes and no trials and equal numbers of each display type. The targets and displays for these trials were constructed using only the digits 0 and 1. (Thus, unlike in the experimental trials, nonredundant practice trials included multiple instances of both digits.) In all other respects, the design and procedure were identical to those used in the previous experiments.

\section{Results and Discussion}

The data for Experiment 3 are presented in Table 3. The error rate in this experiment did not vary as a function of display type or response type, nor was the interaction of display type and response type significant ( $F<1$, in all cases). Mean RT was significantly influenced by display type $[F(2,46)=4.112, p<.05]$. Mean RT was lower for redundant displays than for nonredundant displays $[F(1,23)=7.332, p<.05$, collapsed over response type; $F(1,23)=4.789, p<.05$, for yes displays; $F(1,23)=3.808, p<.07$, for no displays]. There was not a significant difference in RT to redundant and single-digit displays $[F(1,23)=1.134$, $p>.25$ ], but RT to single-digit displays was marginally faster than RT to nonredundant displays $[F(1,23)=4.060$, $p<.06]$. Finally, subjects made yes responses more quickly than no responses $[F(1,23)=11.752, p<.01]$;

Table 3

Mean Response Time (RT; in Milliseconds) and Percent Error Rate (PE) as a Function of Display Type and Response in Experiment 3

\begin{tabular}{|c|c|c|c|c|c|c|}
\hline \multirow[b]{3}{*}{ Response } & \multicolumn{6}{|c|}{ Display Type } \\
\hline & \multicolumn{2}{|c|}{ Single } & \multicolumn{2}{|c|}{ Redundant } & \multicolumn{2}{|c|}{ Nonredundant } \\
\hline & RT & PE & RT & PE & RT & PE \\
\hline $\begin{array}{l}\text { Yes } \\
\text { No }\end{array}$ & $\begin{array}{l}519 \\
550\end{array}$ & $\begin{array}{l}6.79 \\
6.71\end{array}$ & $\begin{array}{l}518 \\
540\end{array}$ & $\begin{array}{l}6.29 \\
6.92\end{array}$ & $\begin{array}{l}535 \\
551\end{array}$ & $\begin{array}{l}6.75 \\
6.21\end{array}$ \\
\hline Mean & 534 & 6.75 & 529 & 6.60 & 543 & 6.48 \\
\hline
\end{tabular}


this effect did not interact with that of display type $[F(2,46)$ $=1.240, p>.25]$.

These results demonstrate that the redundancy effect occurs for stimuli other than letter strings. Assuming that the nonredundant displays were not more familiar to the subjects than were the redundant displays, these results also provide evidence against accounts of the redundancy effect based on response-level competition between letter and pattern-unit representations.

\section{EXPERIMENT 4}

In the previous experiments, redundancy effects were found both for mixed-case letter displays (Experiment 1) and for digit displays (Experiment 3). In both cases, redundant and nonredundant displays differed in whether the context items included instances of the critical item. In contrast, when the critical item was not also present elsewhere in the display, the relationships among the context characters had no effect (i.e., in Experiment 2, wherein the critical items were letters and the context items were digits). This pattern of results suggests that information about the identities of the context items is directly influencing either perceptual or decision processes.

In the introduction it was pointed out that Johnson and Blum (1988) had provided arguments against this kind of hypothesis. Johnson and Blum argued that if information about the identities of the context letters directly influences processing, responses should be slowed by the presence of the target letter in noninitial positions of no displays. However, Johnson (1986a) failed to observe such an effect. In that study, responses to four-letter nonredundant no displays containing the target in a noninitial position were only $6 \mathrm{msec}$ slower than responses to nonredundant no displays in which the target was not present in any position. This suggests that information about the identities of the context letters is not responsible for the slower processing of nonredundant displays.

However, a hint that such information is influencing processing can be found in Johnson's (1986a) data. Responses, when considered as a function of the position of the noninitial target distractor, were slowest when the distractor was adjacent to the critical item $(710 \mathrm{msec})$ and faster when the distractor appeared in the other positions (694 and $686 \mathrm{msec}$ in the third and fourth positions, respectively). Although this effect was not statistically reliable, it at least suggests that information about noninitial distractors was influencing RT and that the size of this effect depended on the distance between the critical letter and the target.

Thus, in the fourth experiment, target distractors were embedded in the context letters of nonredundant displays. Four types of displays were presented. The redundant and no-distractor nonredundant displays were similar to those used in the previous experiments (except that only upper- case letters were used). The near-distractor displays were similar to the nonredundant displays, except that the letter in the second position was always the target letter. Thus, on near-distractor yes trials, the first two letters of the display were identical and were different from the letters in the other three positions (e.g., BBVND). On neardistractor no trials, the second letter was identical with the target, but the first and second letters were not the same (e.g., CBVND, with B as the target). The logic was the same for the far-distractor displays, except that the distractor now appeared in the fifth position (e.g., BRVNB and CRVNB for the yes and no displays, with $\mathrm{B}$ as the target in both cases).

If information about the identities of the noninitial letters is responsible for the redundancy effect, then response latencies should be influenced by the presence of the target letter in noninitial positions. In particular, on no trials, responses should be slowed by the presence of a distractor, because on these trials the distractor would signal an incorrect yes response. On yes trials, the presence of a target in a noninitial position could be expected to result in faster responses for any of a number of reasons. The distractor could directly facilitate the processing of the initial letter, or it could provide additional evidence to the response selection process favoring a yes response. Alternatively, the presence of the distractor could reduce the amount of perceptual or response interference produced by context letters that differ in identity from the initial letter. Additionally, if the degree to which contextletter-identity information influences processing varies with letter position, then the magnitude of these effects should be greater in the near-distractor condition.

\section{Method}

Subjects. Thirty-two Harvard University students served as paid subjects.

Design and Materials. Twenty consonants were used to construct the stimuli ( $Y$ was not used). In the redundant condition, the display consisted of five instances of the same consonant. In the nodistractor condition, the displays consisted of five different consonants, and if the target was present, it only appeared in the initial position. In the near-distractor condition, the second letter was always identical to the target, and, on yes trials, to the initial letter as well. The remaining context letters differed from each other and from the letters in the first two positions. The far-distractor displays were constructed in the same way, except that in this case it was the letter in the fifth position that was always identical to the target. (Note that single-letter displays were not included in this experiment.) For each display condition, each letter appeared equally often in each letter position. Uppercase letters were used both as targets and in the displays.

Each subject performed eight blocks of 60 trials. Each block included 20 redundant displays, 20 no-distractor displays, 10 neardistractor displays, and 10 far-distractor displays. In each block, half of each display type were yes trials and half were no trials. Before completing the 480 experimental trials, each subject performed 12 practice trials. The practice stimuli were constructed from the letters A, E, I, O, U, and Y. These stimuli included 4 redundant displays, 4 no-distractor displays, 2 near-distractor displays, 
and 2 far-distractor displays. Half of the practice trials in each display condition were yes trials. In all other respects, the design and procedure were identical to those used in the previous experiments.

\section{Results and Discussion}

The data from Experiment 4 are presented in Table 4. Neither response type nor display type had a significant main effect on the error rate ( $F<1$, in both cases). The interaction of these variables was significant $[F(3,93)=$ $4.716, p<.01]$ but difficult to interpret. There were more errors on yes trials than on no trials in the redundant and near-distractor conditions, whereas the reverse was true in the no-distractor and far-distractor conditions. However, none of these differences were significant in post hoc analyses that used the Tukey procedure (Keppel, 1982).

Mean RT was lower on yes trials than on no trials $[F(1,31)=13.097, p<.001]$. In addition, the effect of display type was also significant $[F(3,93)=6.219$, $p<.001]$, as was the interaction of display type and response type $[F(3,93)=13.032, p<.001]$. As in the previous experiments, planned comparisons were performed to examine how RT varied with display condition. Collapsed over response type, RT was lower in the redundant condition than in any of the nonredundant conditions $[F(1,31)=20.955, F(1,31)=10.523$, and $F(1,31)=11.493$, for the no-distractor, near-distractor, and far-distractor conditions, respectively, $p<.01$ for each comparison], but there were no reliable differences among the three nonredundant conditions $(F<1$ for all three comparisons).

Given the hypothesis under consideration, the particularly interesting comparisons consider each response type separately. Here, a somewhat different picture emerges. On yes trials, RT was influenced by the presence of the target among the context letters. Mean RT was higher in the no-distractor condition than in either the neardistractor $[F(1,31)=29.972, p<.001]$ or far-distractor $[F(1,31)=4.856, p<.05]$ conditions. Moreover, the magnitude of this effect varied with letter position. Mean RT was lower in the near-distractor condition than in the far-distractor condition $[F(1,31)=5.599, p<.05]$, and although RT on yes trials was lower to redundant displays than to far-distractor displays $[F(1,31)=12.226$, $p<.01]$, there was not a reliable difference in RT be-

Table 4

Mean Response Time (RT; in Milliseconds) and Percent Error Rate (PE) as a Function of Display Type and Response in Experiment 4

\begin{tabular}{|c|c|c|c|c|c|c|c|c|}
\hline \multirow[b]{3}{*}{ Response } & \multicolumn{8}{|c|}{ Display Type } \\
\hline & \multicolumn{2}{|c|}{ Redundant } & \multicolumn{2}{|c|}{$\begin{array}{c}\text { No } \\
\text { Distractor }\end{array}$} & \multicolumn{2}{|c|}{$\begin{array}{c}\text { Near } \\
\text { Distractor } \\
\end{array}$} & \multicolumn{2}{|c|}{$\begin{array}{c}\text { Far } \\
\text { Distractor }\end{array}$} \\
\hline & RT & $\mathrm{PE}$ & RT & $\mathrm{PE}$ & RT & $\mathrm{PE}$ & $\overline{R T}$ & $\mathrm{PE}$ \\
\hline $\begin{array}{l}\text { Yes } \\
\text { No }\end{array}$ & $\begin{array}{l}457 \\
491\end{array}$ & $\begin{array}{l}5.59 \\
6.38\end{array}$ & $\begin{array}{l}481 \\
492\end{array}$ & $\begin{array}{l}6.91 \\
5.12\end{array}$ & $\begin{array}{l}462 \\
514\end{array}$ & $\begin{array}{l}5.12 \\
6.88\end{array}$ & $\begin{array}{l}474 \\
500\end{array}$ & $\begin{array}{l}6.84 \\
5.56\end{array}$ \\
\hline Mean & 474 & 5.98 & 486 & 6.02 & 488 & 6.00 & 487 & 6.20 \\
\hline
\end{tabular}

tween the redundant and near-distractor conditions $[F(1,31)=1.119, p>.25]$.

Mean RT was also influenced by the presence of a distractor on the no trials, but, in this case, the effect was detrimental. Mean RT in both the near- and far-distractor conditions was greater than in either the redundant [near, $F(1,31)=11.829, p<.01 ;$ far, $F(1,31)=5.758$, $p<.05$ ] or no-distractor [near, $F(1,31)=13.291$, $p<.01$; far, $F(1,31)=3.405, p<.08]$ conditions. In addition, no responses were $14 \mathrm{msec}$ slower to neardistractor displays than to far-distractor displays, but this difference only approached statistical significance $[F(1,31)$ $=2.605, p<.12]$.

Thus, the present results support the conclusion that the presence of the target in noncritical letter positions is a critical factor underlying the redundancy effect. Before considering the implications of this finding, however, one point about the methodology of Experiment 4 should be noted. Yes and no distractor trials differed, in that only yes displays included two tokens of the same letter (i.e., the target appeared as both the initial letter and a distractor on yes trials but only as a distractor on no trials). Thus, the subjects could have adopted the strategy of responding yes whenever they noticed a matching pair of letters in the display. If matched pairs were occasionally detected faster than the subjects could determine that the initial letter was the target, and if the match detection process is faster when the letters are adjacent, then one would obtain the observed pattern of results on yes trials. Note, however, that this account does not explain why distractors slowed responses on nonredundant no trials, as all nonredundant no displays contained five different letters regardless of whether one of them was a distractor.

\section{GENERAL DISCUSSION}

The present results support a number of conclusions about the nature of the redundancy effect and the processes that underlie it. First, the process of deciding whether the critical letter matches the target letter is influenced by information about the identities of the noninitial letters. Yes responses are made more quickly when the target letter is present among the context letters; no responses are slowed under the same conditions. Moreover, the effect of noninitial target letters was greater when they were adjacent to the critical letter than when they occupied a more distant position, although this distance effect was significant only on yes trials. 1

Second, it is unlikely that the redundancy effect occurs because subjects must check that the response is based on the initial letter of nonredundant displays but can opt not to carry out this check with redundant displays (Johnson \& Blum, 1988). No redundancy effect was found in the blocked condition of Experiment 1, in which subjects were given advance information that could have allowed them to adopt this strategy. However, a redundancy effect was found in the unblocked condition, wherein redundant displays lacked the physical regularity that, as John- 
son and Blum suggested, provides subjects with the information that a positional check is unnecessary. The position-checking hypothesis also fails to account for the results of Experiment 4-it does not explain why response latencies to nonredundant displays are influenced by the presence of one target letter among the context items.

A third conclusion is that the redundancy effect is not dependent on the homogeneity of either the entire display or the context characters. The redundancy effect occurs regardless of whether the displays consist of uppercase or mixed-case letters. Conversely, the redundancy effect does not occur when the target and critical items are letters and the context items are digits, regardless of the physical regularity of the context items.

Finally, it is unlikely that the redundancy effect occurs because there is more competition between pattern-level and letter-level information in the processing of nonredundant displays. It is at least plausible that nonredundant letter strings are more likely to resemble familiar words than are redundant letter strings, and thus that performance with nonredundant displays could suffer more from the effects of interlevel interference on either perceptual or response processes. However, it seems less likely that redundant and nonredundant digit strings differ in their familiarity, and yet digit displays also give rise to a redundancy effect, as was demonstrated in Experiment 3. Experiment 4 provides additional evidence against this account. It seems unlikely that nonredundant displays systematically differed in familiarity as a function of whether they contained the target letter in a noninitial position. Even if this was the case, differences in familiarity must have opposite effects on yes and no trials in order to account for the results. (This is not to argue that familiarity has no effect on tasks of this sort; see Johnson, 1986a; Johnson et al., 1986.)

The present results bear both similarities and differences with those of other studies employing focused attention tasks. For example, C. W. Eriksen and his colleagues (e.g., B. A. Eriksen \& C. W. Eriksen, 1974; C. W. Eriksen \& Schultz, 1979) employed a "flankers" task, in which two sets of possible target letters were paired with different manual responses, and the subject's task was to indicate which set included the middle letter of a threeor five-letter display. As in the present paradigm, RT in the flankers task is influenced by the relationship between the critical and context letters: Responses are faster when the critical and context letters belong to the same target set than when they belong to different sets (C. W. Eriksen \& Schultz, 1979).

Yantis and Johnston (1990) employed both a yes/no detection task like that of the present study and a twoalternative forced-choice procedure like that of $\mathrm{C}$. W. Eriksen and Schultz (1979). The stimulus displays consisted of letters arranged in a circle, and, in the conditions most relevant to the present discussion, the location of a target letter was cued prior to the presentation of the display. Unlike the large redundancy effects found in the present study and elsewhere (e.g., C. W. Eriksen \&
Schultz, 1979; Johnson, 1986a, 1986b; Johnson \& Blum, 1988), the redundancy effects found by Yantis and Johnston were small (in fact, often negligible) and could be attributed entirely to the context letters that appeared closest to the cued position.

Yantis and Johnston (1990) proposed that, in performing a focused attention task, subjects use an attentional filter that allows feature information from the attended region to drive identification and response processes while preventing information from unattended regions from influencing those processes. They also suggested that, although selection can be highly effective, information from to-be-ignored regions might leak through the filter when attention is ineffectively or incompletely focused, with the amount of leakage varying inversely with the distance from the attended region.

Yantis and Johnston (1990) argued that the conditions of their study were favorable to the allocation of an early selective filter, resulting in the context letters having but a minimal influence on performance. They also suggested that paradigms such as those employed by C. W. Eriksen and Schultz (1979) and Johnson and Blum (1988) incorporate factors that minimize the effectiveness of the attentional filter. In particular, the stimulus configurations tend to include letters that are close together and that are arranged in strings resembling words (which people appear to treat as single units in allocating attention; see LaBerge, 1983). In addition, in these paradigms, the critical position remains constant over trials, and it appears that attention to a given visual area tends to habituate over time (Posner, Snyder, \& Davidson, 1980).

This line of reasoning suggests that the Yantis and Johnston (1990) account can explain the results of the present study as well. According to this account, the effectiveness of the selective filter was limited by the stimulus configuration and by the fact that the critical letter always appeared in the first position. Because the filter was "leaky," feature information from to-be-ignored letter positions influenced subsequent identification and response processes.

There are several ways in which this might occur. One way is that feature information from noninitial positions could influence the identification of the initial letter. For example, on redundant trials, feature information from noninitial positions might provide evidence that speeds the identification of the letter in the initial position, whereas on nonredundant trials, the same information would slow the identification process by providing conflicting evidence about the identity of the initial letter. Because RT is a direct function of the time needed to identify the initial letter, such a mechanism would produce the observed pattern of results.

Alternatively, if the letters in a display are identified in parallel (to the degree that the selective filter allows), then feature information from noninitial letters need not directly influence the identification of the initial letter in order to influence response latencies. In particular, if the decision process cannot completely ignore the output of 
the processing channels responsible for identifying the noninitial letters, then decisions will be made faster when each channel provides the same information than when each channel signals that a different letter was present. In addition, to account for the effect of noninitial distractors on no trials, it must be assumed that the response process is particularly sensitive to information suggesting that the target is present in the display. Given that subjects receive the target before they see the display, this does not appear to be an unreasonable assumption.

To summarize, the central assumption of this general account is that the redundancy effect occurs because information about to-be-ignored positions leaks through the attentional filter and is combined with information about the initial letter. The alternative versions of the account differ on whether this integration occurs during the identification or response stage.

There are several points to be made about this account. First, Yantis and Johnston (1990) list many of the factors that appear to determine the efficacy of the attentional filter. The present results shed additional light on this issue by suggesting that the efficacy of the filter does not depend on whether the component elements of the display are physically identical. In particular, the redundancy effect occurred with mixed-case stimuli in the unblocked condition of Experiment 1, even though the components of those stimulus displays were not all physically identical. Conversely, in Experiment 2, in which the targets and critical items were letters and the context items were digits, varying the homogeneity of the context items had no effect.

A second point is that even though the burden of the explanation rests primarily on an early selection mechanism, the present results are not incompatible with a "multiple locus" model, in which selection can take place at more than one processing level (see LaBerge, 1983; Pashler \& Badgio, 1985; Yantis \& Johnston, 1990). Indeed, if it is assumed that the late-selection mechanism is leaky, and that the amount of leakage varies with distance from the attended region, then the present results can be explained without invoking the notion of an early filter. However, a purely late-selection account appears incompatible with results from other focused attention studies in which unattended stimuli have little or no effect on performance (see Yantis \& Johnston, 1990, for a complete discussion of this issue). Thus, there is strong evidence supporting the assumption that an early-selection mechanism contributes to the performance of focused attention tasks such as the one employed in the present study.

Finally, it is worth pointing out that even though the notion of an attentional filter takes center stage in this account, the contribution of other processes must also be considered. For example, for the redundancy effect to $\alpha$ cur, postselection processes must be influenced by information about the context items. In addition, it seems likely that the preattentional processing of the critical item is also influenced by information about the context items. In particular, a number of studies (e.g., Bjork \& Murray, 1977; Egeth \& Santee, 1981) have demonstrated that when stimuli are degraded by backward masking, performance decreases with increased target-context similarity, at least partly because of feature-specific lateral inhibition. On the basis of these results, it might be expected that repeated items would interfere with performance when stimuli are not masked as well. However, the finding that redundant items often facilitate performance when stimuli are not degraded (C. W. Eriksen \& Schultz, 1979; Johnson, 1986a, 1986b; Johnson \& Blum, 1988; as well as the present study) suggests that the inhibitory effect of target-context redundancy at the feature-encoding stage is more than compensated for by the facilitatory effect of target-context redundancy during subsequent processes (see Estes, 1982; Shapiro \& Krueger, 1983).

Overall, then, the picture that emerges from these considerations is that of a system in which the processing of an element in a display is influenced in different ways, at different stages, by other elements in the display. Moreover, at least some of these interactions can be controlled by an attentional mechanism, but the efficiency of this mechanism depends on the characteristics of the visual display.

\section{REFERENCES}

BJork, E. L., \&urray, J. T. (1977). On the nature of the input channels in visual processing. Psychological Review, 84, 472-484.

Egeth, H., SANTEE, J. (1981). Conceptual and perceptual components of interletter interference. Journal of Experimental Psychology: Human Perception \& Performance, 7, 506-517.

ERIKSEN, B. A., \& ERIKSEN, C. W. (1974). Effects of noise letters upon the identification of a target letter in a nonsearch task. Perception \& Psychophysics, 16, 143-149.

Eriksen, C. W., \& Schultz, D. W. (1979). Information processing in visual search: $A$ continuous flow conception and experimental results. Perception \& Psychophysics, 25, 249-263.

Estes, W. K. (1982). Similarity-related channel interactions in visual processing. Joumal of Experimental Psychology: Human Perception \& Performance, 8, 353-382.

HeALY, A. F. (1976). Detection errors on the word the: Evidence for reading units larger than letters. Journal of Experimental Psychology: Human Perception \& Performance, 2, 235-242.

HENDERSON, L. (1982). Orthography and word recognition in reading. New York: Academic Press.

JoHnson, N. F. (1986a). On looking at letters within words: Do we "see" them in memory? Joumal of Memory \& Language, 25, 558-570.

JoHNSON, N. F. (1986b). On the detection of letters within redundant arrays. Perception \& Psychophysics, 40, 93-100.

JoHnson, N. F., \& BLuM, A. (1988). When redundancy hurts letter detection: An attempt to define one condition. Perception \& Psychophysics, 43, 147-155.

Johnson, N. F., Turner-Lyga, M., Pettegrew, B. S. (1986). Partwhole relationships in the processing of small visual patterns. Memory \& Cognition, 14, 5-16.

Johnston, J. C., \& MCClelland, J. L. (1980). Experimental tests of a hierarchical model of word identification. Joumal of Verbal Learning \& Verbal Behavior, 19, 503-524.

KEPPEL, G. (1982). Design and analysis: A researcher's handbook (2nd ed.). Englewood Cliffs, NJ: Prentice-Hall. 
Krueger, L. E., \& Shapiro, R. G. (1980). Repeating the target neither speeds nor slows its detection: Evidence for independent channels in letter processing. Perception \& Psychophysics, 28, 68-76.

LABERGE, D. (1983). Spatial extent of attention to letters and words. Joumal of Experimental Psychology: Human Perception \& Performance, 9, 371-379.

McClelland, J. L., Rumelhart, D. E. (1981). An interactive activation model of context effects in letter perception: Part 1. Psychological Review, 88, 375-407.

Pashler, H., Badgio, P. C. (1985). Visual attention and stimulus identification. Journal of Experimental Psychology: Human Perception \& Performance, 11, 105-121.

Posner, M. I., Snyder, C. R. R., DAvidson, B. J. (1980). Attention and the detection of signals. Journal of Experimental Psychology: General, 109, 160-174.

Reicher, G. M. (1969). Perceptual recognition as a function of the meaningfulness of stimulus material. Joumal of Experimental Psychology, 81, 275-280.

Shapiro, R. G., \& Krueger, L. E. (1983). Effect of similarity of surround on target-letter processing. Journal of Experimental Psychology: Human Perception \& Performance, 9, 547-559.
Wheeler, D. D. (1970). Processes in word recognition. Cognitive Psychology, 1, 59-85.

Yantis, S., Johnston, J. C. (1990). On the locus of visual selection: Evidence from focused attention tasks. Joumal of Experimental Psychology: Human Perception \& Performance, 16, 135-149.

\section{NOTE}

1. It is tempting to suppose that the influence of the distractor is a monotonic function of this distance. However, because distractors in the far-distractor condition appeared in the rightmost letter position, the processing of those letters most likely suffered less from lateral masking than did the processing of interior letters. Thus, it is not clear that had distractors appeared in Positions 3 or 4, their influence would have been as great or greater than that of the distractors in the far condition.

(Manuscript received June 25, 1990; revision accepted for publication December 19, 1990.) 